\title{
A New Approach to The Pathogenesis of Down Syndrome: An Integrated Quantitative Neuro- Transcriptome Analysis of Several Brain Areas in Human Trisomy 21.
}

\author{
Alejandra Rodriguez-Ortiz \\ Universidad del Valle \\ Julio Cesar Montoya Villegas \\ Universidad del Valle \\ Adalberto Sánchez-Gomez \\ Universidad del Valle \\ José María Satizábal Soto \\ Universidad del Valle \\ Yecid Mina-Paz ( $\square$ yecid.mina@correounivalle.edu.co) \\ Institución Universitaria Escuela Nacional del Deporte \\ Felipe García-Vallejo \\ Universidad del Valle
}

\section{Research Article}

Keywords: Transcriptomics, Brain, Down syndrome, Hippocampus

Posted Date: February 10th, 2021

DOl: https://doi.org/10.21203/rs.3.rs-176627/v1

License: (c) (1) This work is licensed under a Creative Commons Attribution 4.0 International License.

Read Full License 


\section{Abstract}

Background: Although Down syndrome (DS) is a trisomy of chromosome 21 being the most frequent human chromosomal disorder mainly associated with variable levels of intellectual disability and other dysfunctions, the only dose disbalance effect would not enough to explain its genetic and functional complexity neurophenotype. In this context, we aimed to analyze and compare the disruption of transcriptome of several brain areas from individuals with DS and euploid controls as a new approach to consider a global systemic differential disruption of gene expression beyond of chromosome 21 .

Methodology: To perform the analysis carried out in the present study, we used data from a DNA microarray experiment with ID GSE59630 previously deposited in the GEO DataSet of NCBI database. The array contained log2 values of 17,537 human genes expressed in several aeras of human brain. The data was collected from 58 postmortem brain samples of individuals with DS and 58 samples from euploid controls. We calculated the differential gene expression (Z-ratio) of all genes from the microarray according to the several brain areas, gene distribution per chromosome and age ranks.

Results: We found several differences in gene expression along the DS brain transcriptome, not only in the genes located at chromosome 21 but in other chromosomes. Moreover, we registered the lowest Zratio correlation between the age ranks of $16-22$ weeks of gestation and 39-42 years $\left(R^{2}=0.06\right)$ and the highest Z-ratio correlation between the age ranks of 30-39 years and $40-42$ years $\left(R^{2}=0.89\right)$. The analysis per brain areas showed that the hippocampus and the cerebellar cortex had the most different gene expression pattern when compared to the brain as a whole.

Conclusions: Our results revealed the complexity of gene expression networks in the transcriptome profiles of hippocampus, dorsolateral prefrontal cortex (DFC) and cerebellar cortex (CBC). Moreover, our approach opens a new vision of the genomic complexity of DS as a pathology of multiple and complex variables that are playing altogether to modeling their pathogenesis.

\section{Introduction}

Down syndrome (DS) is one of the few chromosomal abnormalities compatible with postpartum survival, with a frequency of 1 in 700 live births and 1 in 150 conceptions [1]. However, depending on sociocultural variables there are notable epidemiological differences among several countries [2]. A remarkable fact is that frequency of DS is much higher at conception, given that up to $75 \%$ and $50 \%$ of DS fetuses identified during the first and second trimester, respectively, are lost before term $[3,4]$. There is strong evidence that most of the errors that lead to the trisomic condition are generated during meiotic processes, in which approximately $90 \%$ of the cases involving a 21 chromosome from maternal origin $[5,6]$.

DS is the most frequent human chromosomal disorder with a complex and variable clinical presentation, and it causes mainly intellectual disability (ID). Individuals with DS also frequently develop Alzheimer disease by the fourth decade [7], and the severity of their cognition impairment is highly variable [8-9]. 
Despite of the huge volume of knowledge about DS, the detailed molecular mechanisms of it neuropathogenesis still remain not fully understood $[10,11]$.

Up to now, two different hypotheses have been proposed to explain DS phenotype: "Developmental instability" [12] and "Gene-dosage effect" [13]. According to the first hypothesis, the presence of an extra Hsa21, globally disturbs the correct balance of gene expression in DS cells during development that produce a non-specific disturbance of genomic regulation and expression, which lead to a disruption of homeostasis throughout the genome $[14,15]$. On contrary the "gene dosage effect" hypothesis, states that the over-expression of duplicated genes on Hsa21 would directly contributes to different aspects of DS phenotype $[16,17]$.

To determine which one of the two hypotheses is applied to explain the etiology of DS, several gene expression studies have been performed in mouse models or in human tissues and cell lines. In this sense, some methods have been used which include: DNA microarrays, serial analysis of gene expression (SAGE), real-time RT-PCR, RNA-seq or even proteomic approaches [18-23]. Despite of an important number of experimentation activity, the different studies have shown contrasting results, probably due to the tissue specificity, developmental stages, as well as the applied experimental platforms and also statistical techniques used. However, altogether suggest that both hypotheses are not mutually exclusive and propose that complex processes are operating in the DS phenotype could probably results by both mechanism [24-26].

Since the brain is the structure involved in the cognitive and mental disability as principal traits of DS neurophenotype, in the present study we analyze the differential transcriptomic profiles of some areas of DS brain in order to get integrated massive data about gene over-expression along several important areas of human brain associated with learning and memory. Our results revealed the complexity of gene expression and interacting networks in the transcriptome profiles of hippocampus and some areas of frontal lobe, occipital lobe, temporal lobe and CBC. Moreover, our approach opens a new vision of the DS as a pathology of multiple and complex genomic variables that are playing altogether to modeling its pathogenesis.

\section{Methodology}

\section{Data mining}

We analyzed the differential gene expression of a brain transcriptome experiment including 17,537 human genes. For all calculations performed in this study we used the log2 transformed expression values of free access DNA microarray experiment whose registration code in the GEO database was GSE59630 (http://www.ncbi.nlm.nih.gov/geo/query/acc.cgi?acc=GSE59630), which was previously deposited by Olmos et al. [27]. The selected microarray experiment included gene expression data of 17,537 genes from 58 post-mortem brain samples of DS patients ( 25 from females and 33 from males) and 58 euploid samples as normal controls ( 25 from females and 33 from males), classified by gender, age and brain areas including: Hippocampus (HIP), cerebellar cortex (CBC), and some cerebral cortex 
structures corresponding to the Dorsolateral prefrontal cortex (DFC), Orbital prefrontal cortex (OFC), Ventrolateral prefrontal cortex (VFC), Medial prefrontal cortex (MFC), Primary somatosensory cortex (S1C), Inferior parietal cortex (IPC), Primary visual cortex (V1C), Superior temporal cortex (STC), Inferior temporal cortex (ITC). Nevertheless, for the present study we decided to analyze not only the brain as a whole but also OFC, MFC, HIP and CBC brain regions which are highly associated to neurophenotype of DS.

\section{Differential gene expression quantification}

Raw intensity log2 data of each experiment which were used for the calculation of Z-score [28]. Z-scores of the protein coding genes analyzed, were calculated according to the equation (1):

$$
Z-\text { score }=\frac{(\text { Log intensity of } G-\text { mean } \log \text { intensity } G \ldots G n)}{\text { Standard Deviation } \log G \ldots G n}
$$

Equation 1. Z-score formula

All Z-score values were normalized on a linear scale $-3.0 \leq 0 \geq+3.0$ (two-tailed $P$ value $<0.001$ ). From Zscore data we calculated the mean values per gene and per structure in brain samples of DS and euploid controls. This data was used to calculate the Z-ratio (Equation 2) with is a measurement that estimate differential gene expression. So, those genes with Z-ratio values over 1.96 are considered over-expressed [28].

$$
Z-\text { ratio }=\frac{\left[\left(Z-\text { score }_{\text {G1ave }}\right) D S-\left(Z-\text { score }_{\text {G1ave }}\right) \text { Con }\right]}{S D \text { of } Z-\text { score differences }}
$$

Equation 2. Z-ratio formula

\section{Statistical analysis}

Statistical analyses for comparing mean values of Z-ratio were performed among the different brain cortex structures between DS patients and euploid controls. The Wilcoxon signed-rank test/Two-tailed was used to calculate differences between medians of two samples. The $p$-values were calculated using the web tool P-value from Z-score Calculator

(https://www.socscistatistics.com/pvalues/normaldistribution.aspx). In all cases we use an alpha 0.05 to test the significance of $\mathrm{H}_{0}$. To calculate the statistical differences in the mean log2 values of DS and Controls for gender, age, hippocampus, cerebellar and brain cortex structures, we apply the t-test for two paired samples/Two-tailed test with an alpha of 0.05 . For correlation analysis we used the Microsoft

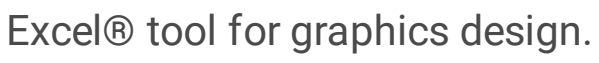

\section{Results}




\section{Differences in the global gene over-expression in brain in chromosomes and structures of Down syndrome individuals.}

Overall, we found that $2.77 \%$ (486/17537) of overexpressed analyzed coding protein genes in brains of DS individuals were differentially distributed along of all human chromosomes. Chromosome 21 accounted for $14.96 \%$ (35/234) of overexpressed genes in the brain of DS samples, followed by chromosome 18 with $3.70 \%$ (10/270), chromosome 8 with $3.10 \%$ (21/677), chromosome $X$ with $3.09 \%$ (26/842), and chromosome 12 with 2.90\% (30/1034). (Table 1).

Nevertheless, every brain structure we analyzed had its own set of overexpressed genes. In some brain cortex areas, the gene overexpression values were variables and depended on the brain structure under analysis. DFC accounted for $3.43 \%(601 / 17,537)$ of gene overexpression; OFC the $2.7 \%(474 / 17,537)$; VFC 2.38\% (418/17,537); ITC 2.37\% (415/17537). However, in HIP 2.43\% $(426 / 17,537)$ and in CBC $2.72 \%$ $(477 / 17,537)$ of genes were overexpressed (table 2).

The most associated GO-Categories biological processes to the over-expressed genes are shown in table 3 with their respective $p$-values (Bonferroni correction). It was predominant the presence of processes associated to epigenetic such as DNA-demethylation (P-value 1.7208E-19), histone deacetylation (P-value 3.4498E-17), Histone H3-K4 methylation (P-value 6.94E-16), and Histone H3-K9 deacetylation (P-value 7.87E-10) (table 3). Figure 1 shows a physical interaction network of genes overexpressed in the brain of DS patients and their most representative functions.

\section{Z-ratio correlations among brain structures and age-ranks}

The correlations calculated among different DS brain structures showed that overexpression in HIP and CBC was particularly different from the one found in the brain as a whole $\left(R^{2}=0.9011\right.$ and $R^{2}=0.9007$ respectively). DFC on the other hand, presented the best correlation with the brain ( $R 2=0.9756)$ (Figure 2$)$.

Moreover, the correlations performed among different age-ranks showed a highly altered pattern dependent of the age rank was calculated. The overexpression found for the rank of 16-22 weeks of gestation showed very low correlation coefficient with the age rank of 39-42 years $\left(R^{2}=0.0628\right), 2-10$ years $\left(R^{2}=0.0708\right)$ and even with $0-12$-month brain samples $\left(R^{2}=0.4242\right)$. However, the best correlation coefficient values were for $12-22$ years with $30-39$ years $\left(R^{2}=0.89\right)$ and $40-42$ years with $30-39$ years $\left(R^{2}=\right.$ 0.90) (Figure 3).

\section{Discussion}

The objective of this study, was to analyse and to compare the transcriptome of brain samples from individuals with DS and euploid controls. For that purpose, we used data from a DNA microarray experiment GSE59630 the contained log2 expression values of 17537 human genes from postmortem brain samples of individuals with DS and samples from euploid controls. Here we found differences in gene expression along the whole transcriptome obtained from brain samples, not only in the genes from 
the chromosome 21; also, the analysis per brain areas showed that the hippocampus and the cerebellar cortex had the most different gene expression pattern when compared to the brain as a whole.

Our findings support the hypothesis of a systemic imbalance of brain protein homeostasis, or proteostasis network of cognitive and neuroplasticity process as an important effect of trisomy not only in loci of chromosome 21 but also in genes located in other chromosomes [29-30]. It is possible that an accumulation of toxic protein aggregates caused by a failed degradative system in DS neurons, negatively affects neuroplasticity processes in brain structures [31-37]. In this sense, our results extended the current knowledge frontier of the neurophysiological mechanisms involved in the disturbance of extensive gene expression, that are remodeling the functional gene networks interaction architecture in DS brains.

One of the most important findings for this study is the global over-expression of over 5000 genes across the transcriptome in every chromosome, not only in chromosome 21 nor even in the called "Down Syndrome Critical Region" as could be expected given that only that DS samples used had a full trisomy confirmed. There are some studies addressing this issue but mainly in murine models. Kahlem et al. [38] found in their study in mice that a significant fraction of genes was differentially regulated in a few tissues, suggesting additional mechanisms affecting gene expression in specific cell types. One of the possible explanations that we propose is the "cascade effect" in which over-expressed transcription factors or epigenome regulators such as HMGN1, located in chromosome 21, affect the expression of other genes located in different chromosomes and thus there is a loss of protein homeostasis in the brain. This could explain how the triplication of one of the smallest chromosomes with approximately 346 genes can cause the over-expression of 482 genes in the brain of Down sndrome. In fact, Kahlem et al. [38] found that most triplicated genes coding for DNA binding proteins, including transcription factors, chromatin proteins, and RNA binding proteins, were overexpressed by a factor of about 1.5 -fold. It is worth noticing that not all genes from chromosome 21 are affected, this is given the dose-compensation presented and documented in trisomy 21 , where we find genes that are dose-sensitive and others not sensitive.

Another interesting finding in the present study, was that GO-categories biological processes associated with the overexpressed genes were mainly focused on epigenetic processes such as DNA methylation and histone deacetylation. Nowadays it would be a mistake disregard the effect that epigenetics have, in combination with genetics, in the development of syndromes, and Down syndrome is not the exception [30]. Genome-wide methylation studies have identified epigenetic marks in different sample tissues from individuals with DS including skin fibroblasts, liver, placenta and brain among others [39].

Our results showed that chromosome 1 had the highest number of over-expressed genes overall, but chromosome 18 had the most over-expressed genes in comparison to the total of protein coding genes found in the chromosome. These results suggest that full trisomy of chromosome 21 affects not only the expression of the genes within chromosome 21, but also the expression of other genes of another different chromosomes. The dysregulation found across the transcriptome could be a "cascade effect", 
initially, due to the anomalous expression of genes in chromosome 21 that regulate the expression of other genes i.e. transcription factors. Specifically, the over-expressed genes in chromosome 21 and 18 are involved mainly in mitochondrial processes. Izzo et al. [40] report how mitochondrial dysfunction might affect the phenotype found in individuals with DS in aspects such as muscle hypotonia, intellectual disability and neurodegeneration, heart defects, type 2 diabetes and obesity, and immune disorders [4142]. The study by Piccoli et al. [43] showed how in human primary lines of DS fetal fibroblasts, trisomy 21 perturbed the expression of genes involved in mitochondrial pathways, decreasing oxygen consumption and ATP content and increasing $\mathrm{mtCa}^{2+}$ load and ROS production. Likewise, lzzo et al. [40] in their study shows how ooverexpressed of human genes on chromosome 21 are directly or indirectly responsible for the pathogenesis of DS phenotypic features, given that, as we stated above, many genes located in chromosome 21 can affect the expression of other genes from different chromosomes. They focused specifically on the involvement of over-expressed genes such as DYRK1A, RCAN1, NRIP1 and ATP in mitochondrial function and energy conversion, leading to mitochondrial dysfunction and chronic oxidative stress which is consistently observed in individuals with DS [44].

According to our results, the expression pattern in the brain of individuals with DS during the pregestational period is completely different from the pattern during the late 30 to 40 years old as it would be expected. The brain during the embryogenesis is still in formation, rearranges in synaptic connection are made throughout the brain by changes in gene expression. In contrast, when a person reaches their 30-40 years, the brain is completely formed and even though they can learn new things and new synapsis connections can be made, the expression pattern does not change drastically. This difference was visible with the negative correlation found when these two age-ranks where compared. The epigenetic here plays a crucial role, the macro and microenvironment that surrounds both age-groups are completely different as shown in our results.

\section{Conclusions}

Overall, our results revealed the complexity of gene expression networks in the transcriptome profiles of hippocampus and some areas of frontal lobe, hippocampus and cerebellar cortex (CBC) which are involved in memory and cognitive process. Moreover, our approach opens a new vision of the DS as a pathology of multiple and complex variables that are playing altogether to modeling their pathogenesis.

\section{Abbreviations}

SD: Down syndrome

CBC: Cerebellar cortex

DFC: Dorsolateral prefrontal cortex

HIP: Hippocampus 
ID: Intellectual disability

SAGE: Serial analysis of gene expression

DNA: Deoxyribonucleic acid

RNA: ribonucleic acid

ATP: Adenosine triphosphate

ROS: Reactive Oxygen Species

OPC: Orbital prefrontal cortex

VFC: Ventrolateral prefrontal cortex

MFC: Medial prefrontal cortex

S1C: Primary somatosensory cortex

IPC: Inferior parietal cortex

V1C: Primary visual cortex

STC: Superior temporal cortex

ITC: Inferior temporal cortex

\section{Declarations}

Ethics approval and consent to participate: Not applicable

Consent for publication: Not applicable

Availability of data and materials: All data generated or analysed during this study are included in this published article. The free access DNA microarray experiment whose registration code in the GEOdatabase was GSE59630 (http://www.ncbi.nlm.nih.gov/geo/query/acc.cgi?acc=GSE59630)

Competing interests: The authors declare that they have no competing interests

Funding: Not applicable

Authors' contributions: AR-O, JCM, FG-V and JMS searched data from a DNA microarray experiment in SD and found microarray experiment with ID GSE59630 previously deposited in the GEO DataSet of NCBI database. AR-O, FG-V, AS and YM-P calculated the differential gene expression (Z-ratio) analysis per brain 
areas. AR-O, YM-P, AS and JCM Gene-dosage imbalanced quantification analysis per brain areas. All authors read and approved the final manuscript.

Acknowledgements: To the Universidad del Valle and the Molecular Biology and Patogenesis research group

Authors information: Not applicable

\section{References}

1. Epstein, Charles J. From Down syndrome to the "human" in "human genetics". The American Journal of Human Genetics. 2002, 70(2), 300-313. doi:10.1086/338915.

2. Stoll C, Alembik Y, Dott B, Roth MP. Study of Down syndrome in 238,942 consecutive births. Ann Genet. 1998;41(1):44-51..

3. Sagi-Dain L, Peleg A, Sagi S. First-Trimester Crown-Rump Length and Risk of Chromosomal Aberrations-A Systematic Review and Meta-analysis. Obstet Gynecol Surv. 2017; Oct;72(10):603-609. doi: $10.1097 / 0 G X .0000000000000490$.

4. Sparks TN, Griffin E, Page J, Pilliod R, Shaffer BL, Caughey AB. Down syndrome: perinatal mortality risks with each additional week of expectant management. Prenat Diagn. 2016; Apr;36(4):368-74 doi: 10.1002/pd.4792. Epub 2016 Mar 14.

5. Hassold T, Sherman S. Down syndrome: genetic recombination and the origin of the extra chromosome 21. Clin Genet. 2000; Feb;57(2):95-100.

6. Ramírez NJ, Belalcázar HM, Yunis JJ, Quintero LN, Arboleda GH, Arboleda H Parental origin, nondisjunction, and recombination of the extra chromosome 21 in Down syndrome: a study in a sample of the Colombian population. Biomedica. 2007; Mar;27(1):141-8. Epub 2007 May 31.

7. Lott I. T. Neurological phenotypes for Down syndrome across the life span. Progress in brain research. 2012; 197, 101-121. doi:10.1016/B978-0-444-54299-1.00006-6.

8. Edgin JO, Mason GM, Allman MJ, Capone GT, Deleon I, Maslen C, et al. Development and validation of the Arizona Cognitive Test Battery for Down syndrome. Journal of Neurodevelopmental Disorders. 2010; a;2:149-164.

9. Roper RJ, Reeves RH Understanding the Basis for Down Syndrome Phenotypes. PLOS Genetics. 2006; 2(3): e50. https://doi.org/10.1371/journal.pgen.0020050).

10. Gardiner, K., Herault, Y., Lott, I. T., Antonarakis, S. E., Reeves, R. H., \& Dierssen, M. Down syndrome: from understanding the neurobiology to therapy. The Journal of neuroscience. 2010; 30(45), 1494314945. doi:10.1523/JNEUROSCI.3728-10.2010.

11. Roizen NJ, Patterson D. Down's syndrome. Lancet. 2003 ; 361: 1281-1289)

12. Pritchard MA, Kola I. The "gene dosage effect" hypothesis versus the "amplified developmental instability" hypothesis in Down syndrome. Neural Transm Suppl. 1999; 57:293-303. 
13. Ait Yahya-Graison E., Aubert J., Dauphinot L., Rivals I., Prieur M., Golfier G., et al. Classification of human chromosome 21 gene-expression variations in Down syndrome: impact on disease phenotypes. Am. J. Hum. Genet. 2007; 81 475-491. 10.1086/520000.

14. Saran N. G., Pletcher M. T., Natale J. E., Cheng Y., Reeves R. H. (2003). Global disruption of the cerebellar transcriptome in a Down syndrome mouse model. Hum. Mol. Genet. 2003; 12(16) 20132019. https://doi.org/10.1093/hmg/ddg217

15. Vilardell M., Rasche A., Thormann A., Maschke-Dutz E., Perez-Jurado L. A., Lehrach H., et al. Metaanalysis of heterogeneous Down Syndrome data reveals consistent genome-wide dosage effects related to neurological processes. BMC Genomics. 2011; 12:229. 10.1186/1471-2164-12-229.

16. Kahlem P. Gene-dosage effect on chromosome 21 transcriptome in trisomy 21: implication in Down syndrome cognitive disorders. Behav Genet. 2006; May;36(3):416-28. Epub 2006 Mar 24.

17. Korenberg J. R. Molecular mapping of the Down syndrome phenotype. Prog. Clin. Biol. Res. 1990; 360 105-115).

18. Lockstone H. E., Harris L. W., Swatton J. E., Wayland M. T., Holland A. J., Bahn S. Gene expression profiling in the adult Down syndrome brain. Genomics. 2007; 90 647-660. 1016/j.ygeno.2007.08.005

19. Prandini P., Deutsch S., Lyle R., Gagnebin M., Delucinge Vivier C., Delorenzi M., et al. Natural geneexpression variation in Down syndrome modulates the outcome of gene-dosage imbalance. Am. J. Hum. Genet. 2007; 81 252-263. 10.1086/519248.

20. Volk M., Maver A., Lovrecic L., Juvan P., Peterlin B. Expression signature as a biomarker for prenatal diagnosis of Trisomy 21. PLoS One. 2013; 8:e74184. 10.1371/journal.pone.0074184

21. Kong X. D., Liu N., Xu X. J. Bioinformatics analysis of biomarkers and transcriptional factor motifs in Down syndrome. Braz. J. Med. Biol. Res. 2014; 47 834-841. 10.1590/1414-431X20143792.

22. Zhao J., Zhang Z., Ren S., Zong Y., Kong X. Co-expression network analysis of Down's syndrome based on microarray data. Exp. Ther. Med. 2016;12 1503-1508. 10.3892/etm.2016.3462.

23. Liu Y., Borel C., Li L., Muller T., Williams E. G., Germain P. L., et al. Systematic proteome and proteostasis profiling in human Trisomy 21 fibroblast cells. Nat. Commun. 2017; 8:1212. 10.1038/s41467-017-01422-6.

24. Letourneau A., Santoni F. A., Bonilla X., Sailani M. R., Gonzalez D., Kind J., et al. Domains of genomewide gene expression dysregulation in Down's syndrome. Nature. 2014; 508 345-350. $10.1038 /$ nature13200.

25. Sullivan K. D., Lewis H. C., Hill A. A., Pandey A., Jackson L. P., Cabral J. M., et al. Trisomy 21 consistently activates the interferon response. eLife. 2016; 5:e16220. 10.7554/eLife.16220.

26. Antonarakis S. E. Down syndrome and the complexity of genome dosage imbalance. Nat. Rev. Gene. 2017; 18 147-163. 10.1038/nrg.2016.154).

27. Olmos-Serrano JL, Kang HJ, Tyler WA, Silbereis JC, Cheng F, Zhu Y, Pletikos M, Jankovic-Rapan L, Cramer NP, Galdzicki Z, Goodliffe J, Peters A, Sethares C, Delalle I, Golden JA, Haydar TF, Sestan N. Down Syndrome Developmental Brain Transcriptome Reveals Defective Oligodendrocyte 
Differentiation and Myelination. 2016; Mar 16;89(6):1208-1222. doi: 10.1016/j.neuron.2016.01.042. Epub 2016 Feb 25. PubMed PMID: 26924435; PubMed Central PMCID: PMC4795969.

28. Cheadle, C., Vawter, M. P., Freed, W. J., \& Becker, K. G. Analysis of microarray data using Z score transformation. The Journal of molecular diagnostics: JMD, 2003; 5(2), 73-81. doi:10.1016/S15251578(10)60455-2

29. Kahlem P, Sultan M, Herwig R, Steinfath M, Balzereit D, Eppens B, Saran NG, Pletcher MT, South ST, Stetten G, Lehrach H, Reeves RH, Yaspo ML. Transcript level alterations reflect gene dosage effects across multiple tissues in a mouse model of down syndrome. Genome Res. 2004; Jul;14(7):1258-67. doi: 10.1101/gr.1951304.

30. Labbadia J, Morimoto RI. The biology of proteostasis in aging and disease. Annu Rev Biochem. 2015; 84:435-64. DOI: 10.1146/annurev-biochem-060614-033955

31. Do C, Xing Z, Yu YE, Tycko B. Trans-acting epigenetic effects of chromosomal aneuploidies: lessons from Down syndrome and mouse models. Epigenomics. 2017; 9(2):189-207. doi: 10.2217/epi-20160138. Epub 2016 Dec 2. Erratum in: Epigenomics. 2017 Mar;9(3):369.

32. El Hajj N, Dittrich M, Böck J, Kraus TF, Nanda I, Müller T, Seidmann L, Tralau T, Galetzka D, Schneider E, Haaf T. Epigenetic dysregulation in the developing Down syndrome cortex. Epigenetics. 2016; 11(8):563-78. doi: 10.1080/15592294.2016.1192736.

33. Valenti D, Braidy N, De Rasmo D, Signorile A, Rossi L, Atanasov AG, Volpicella M, Henrion-Caude A, Nabavi SM, Vacca RA. Mitochondria as pharmacological targets in Down syndrome. Free Radic Biol Med. 2018; 114:69-83. doi: 10.1016/j.freeradbiomed.2017.08.014.

34. Di Domenico F, Coccia R, Cocciolo A, Murphy MP, Cenini G, et al. Impairment of proteostasis network in Down syndrome prior to the development of Alzheimer's disease neuropathology: redox proteomics analysis of human brain. Biochim Biophys Acta. 2013; 1832(8):1249-59. DOI: 10.1016/j.bbadis.2013.04.013.

35. Aivazidis S, Coughlan CM, Rauniyar AK, Jiang H, Liggett LA, et al. The burden of trisomy 21 disrupts the proteostasis network in Down syndrome. PLoS One. 2017; 21;12(4):e0176307. DOI: 10.1371/journal.pone.0176307.

36. Li CM, Guo M, Salas M, Schupf N, Silverman W, Zigman WB, et al. Cell type-specific over-expression of chromosome 21 genes in fibroblasts and fetal hearts with trisomy 21. BMC Med Genet. 2006; 7:24

37. Pagano G, Castello G. Oxidative stress and mitochondrial dysfunction in Down syndrome. Adv Exp Med Biol. 2012; 724:291-9. doi: 10.1007/978-1-4614-0653-2_22.

38. Kahlem P, Sultan M, Herwig R, Steinfath M, Balzereit D, Eppens B, Saran NG, Pletcher MT, South ST, Stetten G, Lehrach H, Reeves RH, Yaspo ML. Transcript level alterations reflect gene dosage effects across multiple tissues in a mouse model of down syndrome. Genome Res. 2004; 14(7):1258-67. doi: 10.1101/gr.1951304

39. Do C, Xing Z, Yu YE, Tycko B. Trans-acting epigenetic effects of chromosomal aneuploidies: lessons from Down syndrome and mouse models. Epigenomics. 2017 Feb;9(2):189-207. doi: 10.2217/epi2016-0138. Epub 2016 Dec 2. Erratum in: Epigenomics. 2017 Mar;9(3):369. 
40. Izzo A, Mollo N, Nitti M, Paladino S, Calì G, Genesio R, Bonfiglio F, Cicatiello R, Barbato M, Sarnataro V, Conti A, Nitsch L. Mitochondrial dysfunction in down syndrome: molecular mechanisms and therapeutic targets. Mol Med. 2018; 24(1):2. doi: 10.1186/s10020-018-0004-y.

41. Park J, Song WJ, Function CKC. Regulation of Dyrk1A: towards understanding down syndrome. Cell Mol Life Sci. 2009; 66:3235-3240. doi: 10.1007/s00018-009-0123-2.

42. Wu Y, Song W. Regulation of RCAN1 translation and its role in oxidative stress-induced apoptosis. FASEB J. 2013; 27(1):208-21. doi: 10.1096/fj.12-213124.,

43. Piccoli C, Izzo A, Scrima R, Bonfiglio F, Manco R, Negri R, Quarato G, Cela O, Ripoli M, Prisco M, Gentile F, Calì G, Pinton P, Conti A, Nitsch L, Capitanio N. Chronic pro-oxidative state and mitochondrial dysfunctions are more pronounced in fibroblasts from Down syndrome foeti with congenital heart defects. Hum Mol Genet. 2013; 22(6):1218-32. doi: 10.1093/hmg/dds529

44. Bartley MG, Marquardt K, Kirchhof D, Wilkins HM, Patterson D, Linseman DA. Overexpression of amyloid-beta protein precursor induces mitochondrial oxidative stress and activates the intrinsic apoptotic cascade. J Alzheimer's Dis. 2012; 28(4):855-868. 10.3233/JAD-2011-111172

\section{Tables}

Table 1. Number and percentage of coding protein genes per chromosome which are over-expressed in Down syndrome patients. 


\begin{tabular}{|c|c|c|c|}
\hline Chromosome & Protein coding genes & Over-expressed genes in DS & Percentage $(* \star)$ \\
\hline 1 & 2,058 & 48 & 2.33 \\
\hline 2 & 1,309 & 22 & 1.68 \\
\hline 3 & 1,078 & 22 & 2.04 \\
\hline 4 & 752 & 19 & 2.53 \\
\hline 5 & 876 & 12 & 1.37 \\
\hline 6 & 1,048 & 31 & 2.96 \\
\hline 7 & 989 & 16 & 1.62 \\
\hline 8 & 677 & 20 & 2.95 \\
\hline 9 & 786 & 14 & 1.78 \\
\hline 10 & 733 & 21 & 2.86 \\
\hline 11 & 1,298 & 29 & 2.23 \\
\hline 12 & 1,034 & 20 & 1.93 \\
\hline 13 & 327 & 9 & 2.75 \\
\hline 14 & 830 & 15 & 1.81 \\
\hline 15 & 613 & 7 & 1.14 \\
\hline 16 & 873 & 19 & 2.18 \\
\hline 17 & 1,197 & 26 & 2.17 \\
\hline 18 & 270 & 8 & 2.96 \\
\hline 19 & 1,472 & 23 & 1.56 \\
\hline 20 & 544 & 14 & 2.57 \\
\hline 21 & 234 & 42 & 16.67 \\
\hline 22 & 488 & 7 & 1.43 \\
\hline$x$ & 842 & 28 & 3.33 \\
\hline Y & 71 & 1 & 1.41 \\
\hline
\end{tabular}

(*). Data from GRCh38.p13". NCBI. Genome Reference Consortium. Retrieved by 08/06/2020

(**) Percentage in each chromosome was calculated from a total of 17,537 protein coding genes reported by Olmos et al. 2016. 
Table 2. Number and percentage of coding protein genes per brain structure which are over-expressed in Down syndrome patients.

\begin{tabular}{|lll|}
\hline Brain Structure & Over-expressed genes & Percentage over the total transcriptome \\
\hline Brain & 486 & 2.77 \\
\hline DFC & 601 & 3.43 \\
\hline OFC & 474 & 2.7 \\
\hline VFC & 418 & 2.38 \\
\hline ITC & 415 & 2.37 \\
\hline HIP & 426 & 2.43 \\
\hline CBC & 477 & 2.72 \\
\hline
\end{tabular}

Table 3. Top ten GO categories - biological processes involving the over-expressed genes in Brain.

\begin{tabular}{|lll|}
\hline GO ID & Description & P-value Bonferroni \\
\hline 9987 & DNA demethylation & $1.72 \mathrm{E}-19$ \\
\hline 43170 & Histone deacetylation & $3.45 \mathrm{E}-17$ \\
\hline 44260 & Histone H3-K4 methylation & $6.94 \mathrm{E}-16$ \\
\hline 19538 & Protein phosphorylation & $3.03 \mathrm{E}-13$ \\
\hline 44267 & Protein polyubiquitination & $1.71 \mathrm{E}-12$ \\
\hline 44237 & ATP synthesis coupled electron transport & $1.98 \mathrm{E}-12$ \\
\hline 8152 & 5 -methylcytosine catabolic process & $5.44 \mathrm{E}-11$ \\
\hline 6464 & MAPK cascade & $2.69 \mathrm{E}-10$ \\
\hline 43687 & Post-translational protein acetylation & $4.42 \mathrm{E}-10$ \\
\hline 43412 & Histone H3-K9 deacetylation & $7.87 \mathrm{E}-10$ \\
\hline
\end{tabular}

\section{Figures}




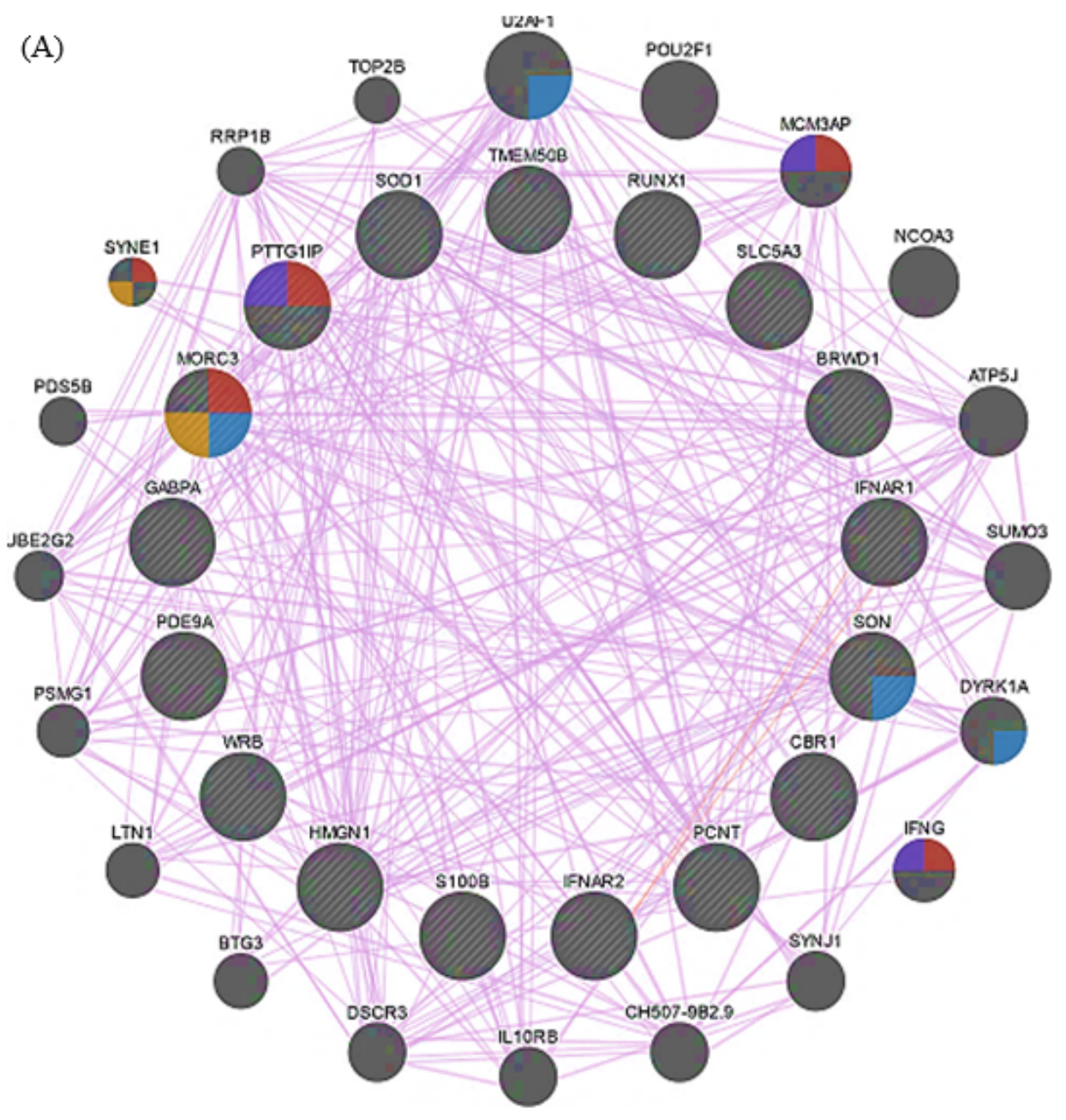

Protein localization to nucleus

Nuclear body

Maintenance of protein location in nucleus

Protein targeting to nucleus

(B)

\begin{tabular}{|l|c|c|c|}
\hline \multicolumn{1}{|c|}{ Function } & FDR & Genes in Network & Genes in Genome \\
\hline Protein localization to nucleus & $5.02 \mathrm{E}-01$ & 5 & 187 \\
\hline Nuclear body & $8.94 \mathrm{E}-01$ & 4 & 163 \\
\hline $\begin{array}{l}\text { Maintenance of protein location in } \\
\text { nucleus }\end{array}$ & $8.94 \mathrm{E}-01$ & 2 & 13 \\
\hline Potein targeting to nucleus & $8.94 \mathrm{E}-01$ & 3 & 58 \\
\hline $\begin{array}{l}\text { Cytokine receptor activity } \\
\text { Nuclear speck, snurposome }\end{array}$ & $8.94 \mathrm{E}-01$ & 3 & 59 \\
\hline
\end{tabular}

\section{Figure 1}

Physical interaction network of genes overexpressed in the brain of Down syndrome patients. Legends: (A). GeneMANIA physical interaction network graphic. (B). Most statistical representative functions of genes overexpressed in the brain of Down syndrome. 
A

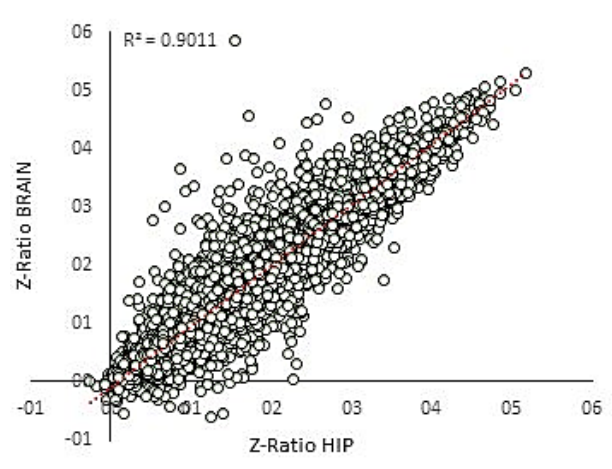

D

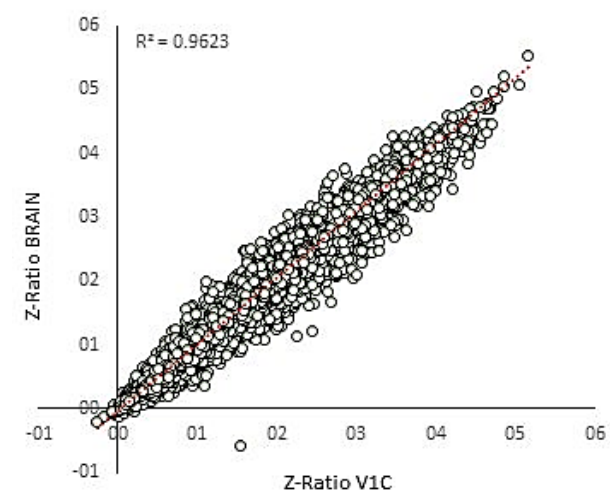

B

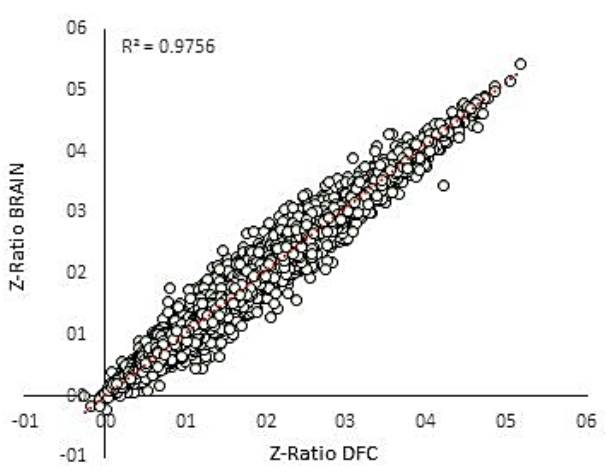

$E$

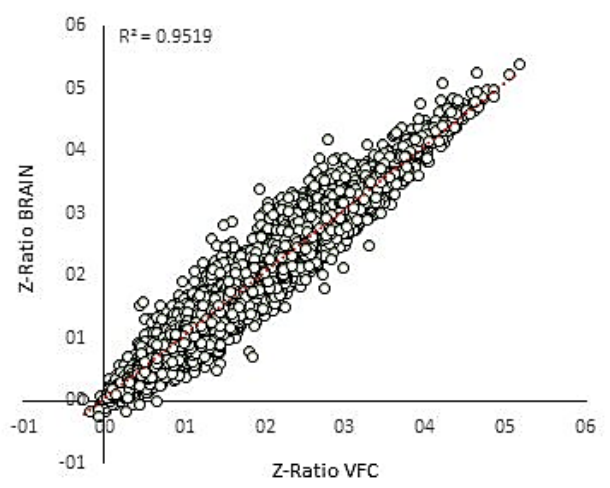

C

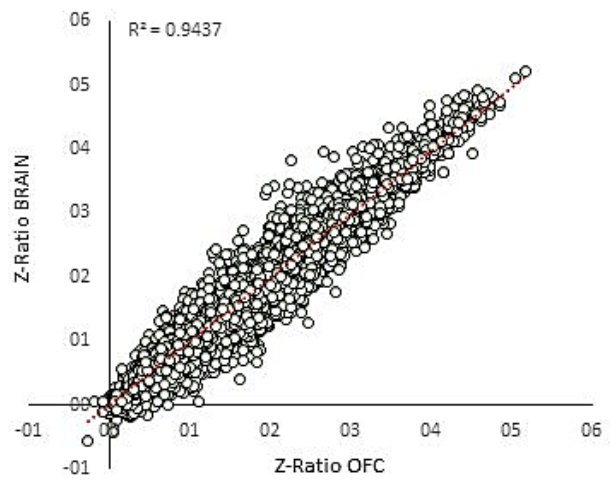

$\mathrm{F}$

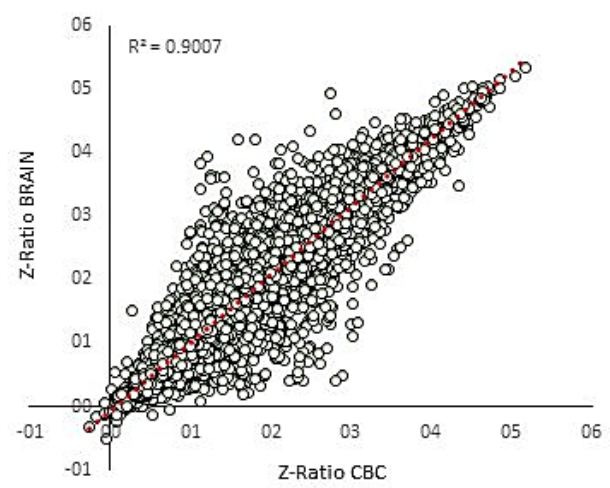

Figure 2

Z-ratio correlation among different brain structures and the brain as a whole. Legends: HIP. Hippocampus, DFC. Dorsofrontal Cortex, OFC. Orbitofrontal Cortex, V1C. Visual Cortex, VFC. Ventrofrontal Cortex, CBC.

Cerebellar Cortex.
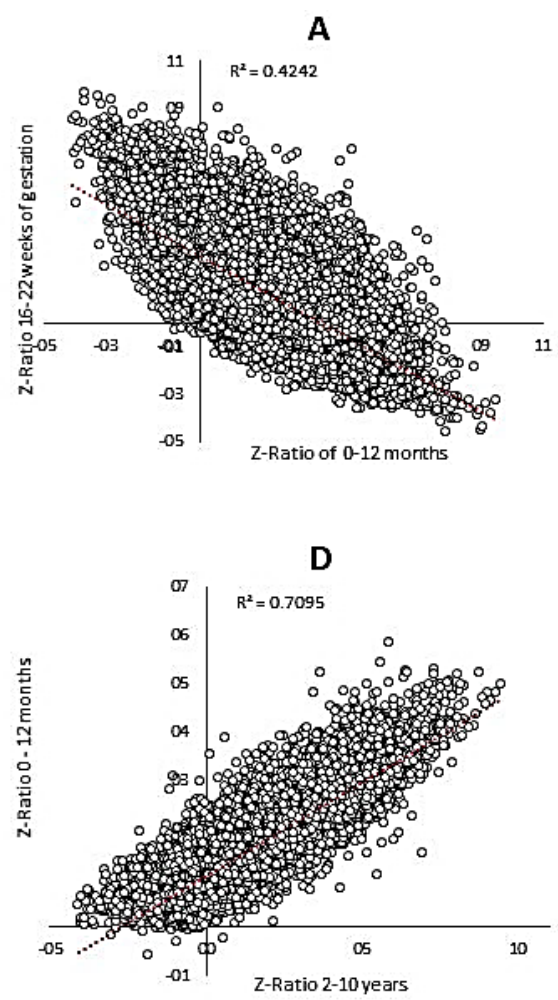
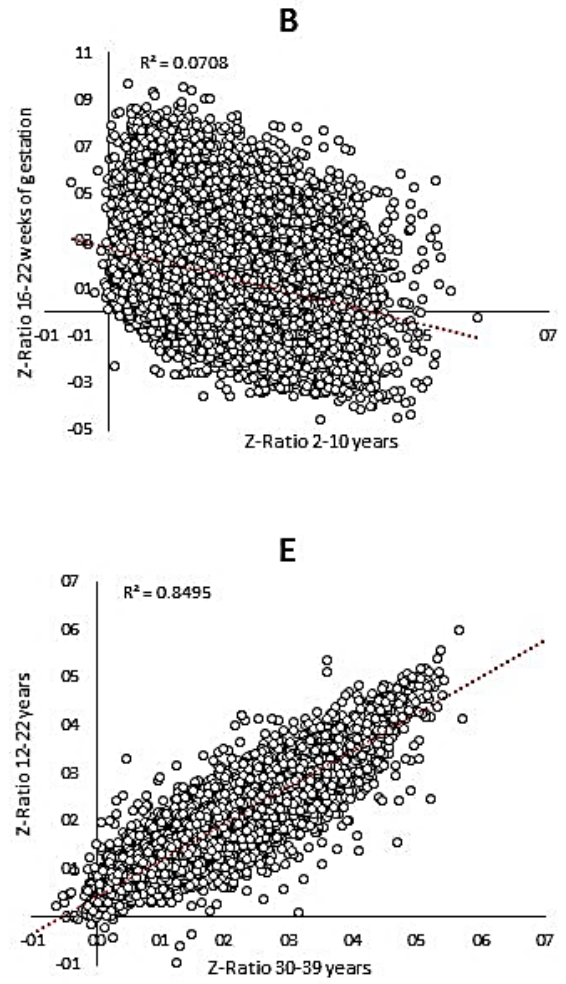
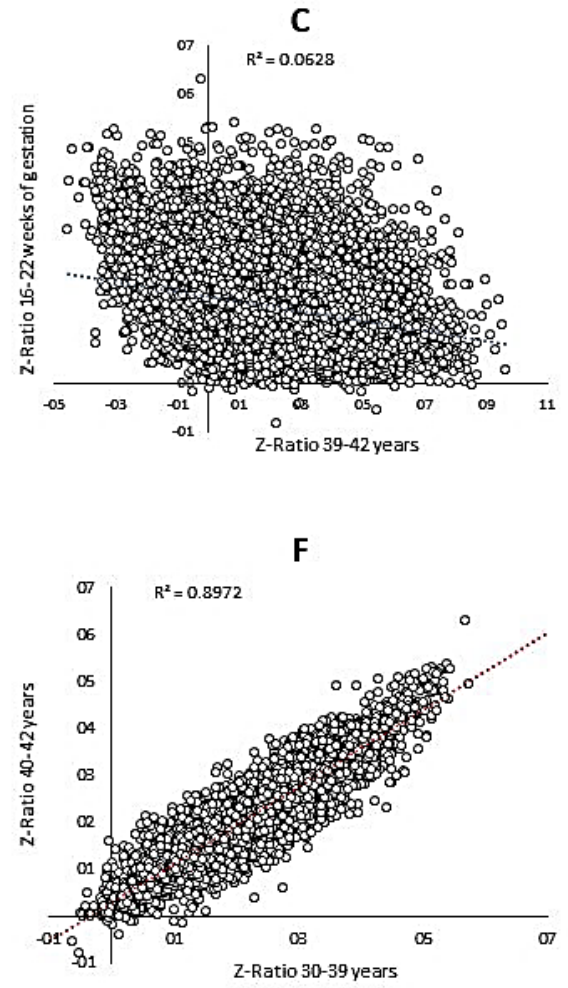
Figure 3

Z-ratio correlation among different age-ranks in the brain samples of Down syndrome 